\title{
On the role of major vault protein in the resistance of senescent human diploid fibroblasts to apoptosis
}

\author{
SJ Ryu', HJ An ${ }^{1}$, YS Oh ${ }^{2}$, HR Choi', MK Ha ${ }^{1}$ and SC Park ${ }^{*, 1}$
}

Major vault protein (MVP), the main component of vault complex, is overexpressed in many multidrug-resistant cancer cell lines, suggesting a possible role for MVP in cell signaling and survival. In this study, we have found that MVP is markedly increased in senescent human diploid fibroblasts (HDFs) as well as in aged organs. We examined whether MVP expression might be affected by apoptotic stress in an aging-dependent manner. We treated young and senescent HDFs with apoptosis-inducing agents such as $\mathrm{H}_{2} \mathrm{O}_{2}$, staurosporine and thapsigargin, and monitored MVP expression. We found that MVP expression is markedly reduced in young HDFs but not in senescent HDFs, in response to apoptotic stresses. Downregulation of MVP increased the sensitivity of senescent HDFs to apoptosis. Also, the level of antiapoptotic B-cell lymphoma protein-2 (Bcl-2) was significantly reduced and the accumulation of $C$-Jun increased in MVP knocked-down senescent HDFs. Moreover, treatment of MVP knocked-down senescent HDFs with SP600125, a specific c-Jun NH(2)-terminal kinase (JNK) inhibitor, restored the level of Bcl-2 protein. Taken together, these results suggest that MVP is important in the resistance of senescent HDFs to apoptosis by modulation of Bcl-2 expression by JNK pathway.

Cell Death and Differentiation (2008) 15, 1673-1680; doi:10.1038/cdd.2008.96; published online 4 July 2008

Vaults are large ribonucleoprotein particles found in a great portion of eukaryotic cells. The vault particle is a multimeric structure composed of three proteins - the major vault protein (MVP), two minor vault proteins, vault poly (ADP-ribose) polymerase (VPARP) and telomerase-associated protein-1 (TP-1), and four small untranslated vault RNAs (vRNAs). ${ }^{1}$ MVP is the main component of the vault complex accounting for $75 \%$ of the total particle mass. ${ }^{2}$ The vault particle has been so named because it has a barrel-shaped structure, reminiscent of the vaulted ceilings in cathedrals. ${ }^{3}$ The interaction of MVP by its coiled coil domain is involved in the formation of the basic vault complex. ${ }^{4}$ MVP expression is upregulated in cancers such as melanoma, ${ }^{5}$ colon cancer $^{6}$ and gliomas $^{7}$ during acquisition of multidrug resistance ${ }^{8,9}$ and during differentiation of dendritic cells. ${ }^{10}$ MVP expression has also been shown to be induced by histone deacetylase inhibitors such as sodium butyrate, ${ }^{11}$ phorbol 12-myristate 13-acetate (PMA) and cytarabine ${ }^{12}$ as well as by cytotoxic drugs. ${ }^{12-14}$ MVP/vaults have been proposed to be important in intracellular transport, ${ }^{15-17}$ innate immunity ${ }^{18}$ and virus infection. ${ }^{19}$ Several studies demonstrated that MVP is important in cell signaling ${ }^{20-22}$ and in cell survival. ${ }^{10,20,23}$ For example, serumdeprived MVP-deficient mouse embryonic fibroblasts (MEFs) exhibit significantly increased cell death when compared with wild-type MEFs. ${ }^{20}$ Therefore, the role of MVP as a scaffolding protein for signaling proteins, especially for cell survival, has received more attention than as a transport vehicle. However, the exact role of MVP in cell survival is not well understood. In this study, we found that apoptotic resistance of senescent human diploid fibroblasts (HDFs) correlates with the increased content of MVP in the senescent cells. This is the first report implicating MVP in apoptosis resistance of senescent HDFs.

\section{Results}

Increased expression of MVP in aged cells and organs. We determined the expression levels of MVP in young and senescent HDFs using cDNA microarray (Figure 1a), RT-PCR (Figure 1b) and western analysis (Figures 1c and d). Expression of MVP in the senescent HDFs was twice that in young HDFs. High levels of MVP were also noted in aged heart, liver, spleen and lung tissues (Figure 1e). We also examined the intracellular distribution of MVP in young and senescent HDFs. As shown in Figures $1 f$ and g, MVP was equally localized in both the cytoplasm and nucleus in contrast to previous studies that reported that the main site of MVP localization is the cytoplasm. ${ }^{15,24}$ We also investigated the basal expression and localization of the minor vault proteins, TP-1 and VPARP, and vRNA (Supplementary Figure 1). We found that VPARP increased slightly, in contrast to TP-1, that changed little, in senescent HDFs (Supplementary Figure 1a). Northern analysis was carried out to determine the expression levels of the four vault RNA species in senescent HDFs and showed markedly increased

\footnotetext{
${ }^{1}$ Department of Biochemistry and Molecular Biology, The Aging and Apoptosis Research Center, Seoul National University College of Medicine, Seoul 110-799, Korea and ${ }^{2}$ Lee Gil Ya Cancer and Diabetes Institute, Gachon University of Medicine and Science, Incheon 406-840, South Korea

*Corresponding author: SC Park, Department of Biochemistry and Molecular Biology, The Aging and Apoptosis Research Center, Seoul National University College of Medicine, 28 Yungon Dong, Chong No Ku, Seoul 110-799, Republic of Korea.

Tel: + 822740 8244; Fax: + 822744 4534; E-mail: scpark@snu.ac.kr

Keywords: apoptosis; senescence; fibroblast; MVP; Bcl-2; JNK

Abbreviations: Bcl-2, B-cell lymphoma protein-2; FACS, fluorescence-activated cell sorter; HDF, human diploid fibroblast; JNK, c-Jun NH(2)-terminal kinase; MEF, mouse embryonic fibroblast; MVP, major vault protein; PARP, poly(ADP-ribose)polymerase; PMA, phorbol 12-myristate 13-acetate; siRNA, small-interfering RNA Received 04.1.08; revised 03.6.08; accepted 04.6.08; Edited by A Villunger; published online 04.7.08
} 


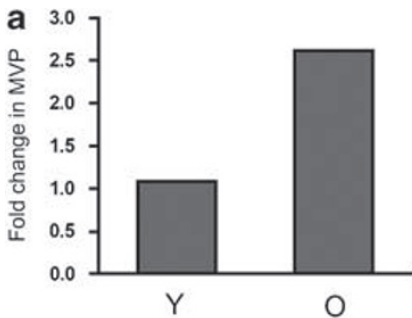

b

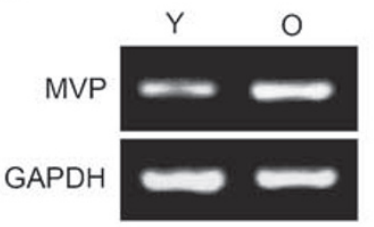

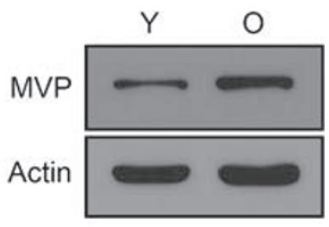

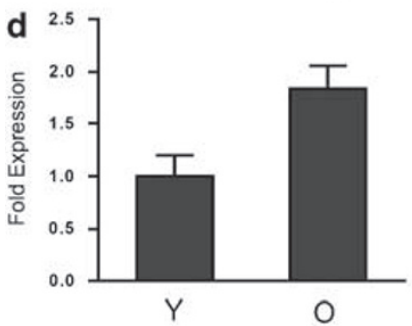

f
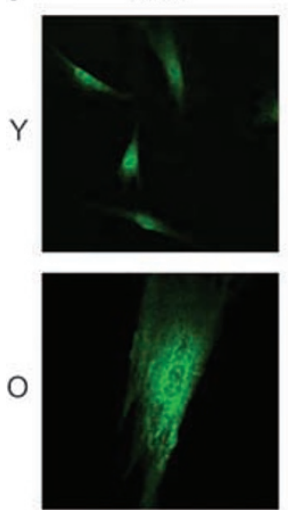

e

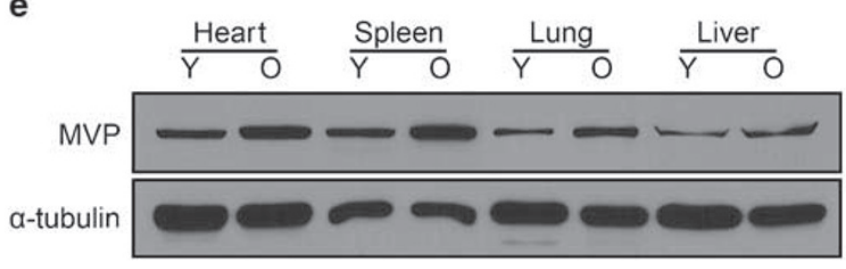

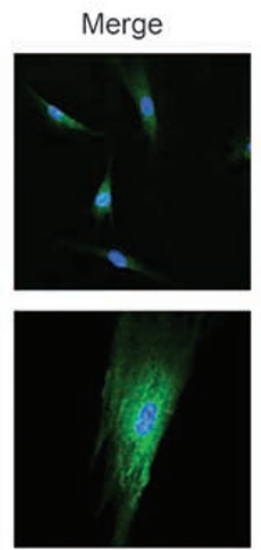

Figure 1 Major vault protein (MVP) is increased in senescent human diploid fibroblasts (HDFs) and old tissues. (a) cDNA microarray for MVP gene expression in young and senescent HDFs. RNA samples from young and senescent HDFs were used to make cDNAs labeled with Cy3 (senescent) and Cy5 (young). The mRNA and protein expressions of MVP were determined by RT-PCR using specific MVP primer (b) and western analysis using anti-MVP antibody (c). (d) Quantitative graph of MVP protein. The results shown are representative of three independent experiments; the histograms represent the average and the error bars represent the standard deviation of the means. (e) Expression of MVP in young and old mouse tissues. Tissues obtained from young and old mice as described in Materials and Methods. Subcellular localization of MVP in young and senescent HDFs was detected by immunostaining (f) and subcellular fractionation (g). Y, young HDFs; O, senescent HDFs; Cox-1, Cyclooxygenase-1; H3, Histone 3; Green, MVP; Blue, nuclei; C, cytosol; N, nucleus; Cox-1, cytosolic marker; H3, nucleus marker

hvg1 but no detectable vRNAs (Supplementary Figure 1b). As shown in Supplementary Figures 1c and d, TP-1 was mainly localized in the cytoplasm of both young and senescent HDFs and only slightly in the nucleus. VPARP was primarily localized in the cytoplasm of young HDFs, but equally in both the cytoplasm and nucleus of senescent HDFs.

Age dependence of MVP expression in response to apoptotic stress. Major vault protein is upregulated by PMA and trichostatin and downregulated by TNF- $\alpha{ }^{12,25,26} \mathrm{We}$ previously reported that senescent HDFs, in contrast to young HDFs, are resistant to apoptosis induced by stresses such as $\mathrm{H}_{2} \mathrm{O}_{2}$, staurosporine and thapsigargin, and that modulation of the expression of B-cell lymphoma protein-2 $(\mathrm{Bcl}-2)$ is important in the apoptotic resistance of senescent cells. $^{27}$ To examine whether MVP expression might be affected by apoptotic stress, we treated young and senescent HDFs with $1.5 \mathrm{mM} \mathrm{H}_{2} \mathrm{O}_{2}, 100 \mathrm{nM}$ staurosporine and $100 \mathrm{nM}$ thapsigargin for various time periods and examined MVP expression in each case. We found that MVP expression, following these treatments, was markedly reduced in young HDFs (Figure 2a) but not in senescent HDFs (Figure 2b). RT-PCR studies using a specific MVP primer revealed that MVP-specific mRNA levels were downregulated in stress-induced young HDFs but not in senescent HDFs (Figures $2 \mathrm{c}$ and $\mathrm{d}$ ), suggesting that downregulation of MVP in young HDFs occurs at the transcriptional level. To determine whether or not the reduction of MVP is mediated by caspase in apoptotic drug-treated young HDFs, we treated young HDFs with caspase inhibitor, Z-VAD (OMe)-FMK, followed by $\mathrm{H}_{2} \mathrm{O}_{2}$ or staurosporine for indicated times (Supplementary Figure 2). We found that the reduction in MVP was prevented by treatment with the caspase inhibitor. This indicates that the loss of MVP is a consequence of apoptosis. Next, we further investigated the subcellular localization of MVP in $\mathrm{H}_{2} \mathrm{O}_{2}$, staurosporine or thapsigargin-treated young and senescent HDFs at early times. As shown in Supplementary Figure 3, we observed that MVP was more localized in cytoplasm by 


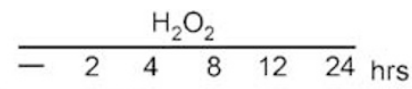

Actin

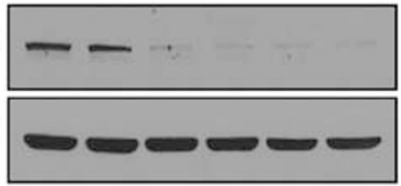

b
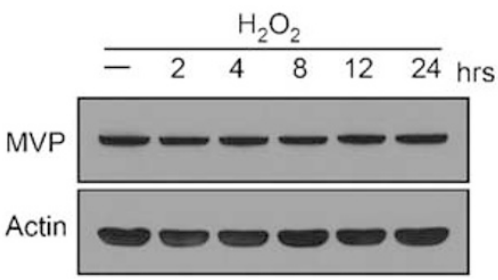

C

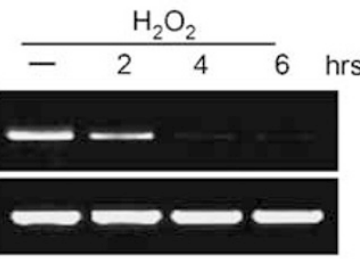

d

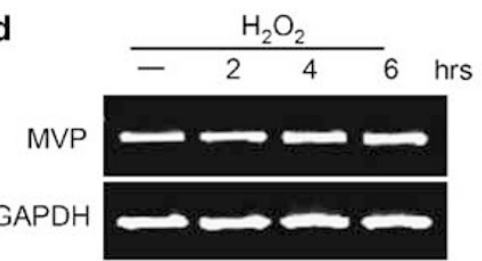

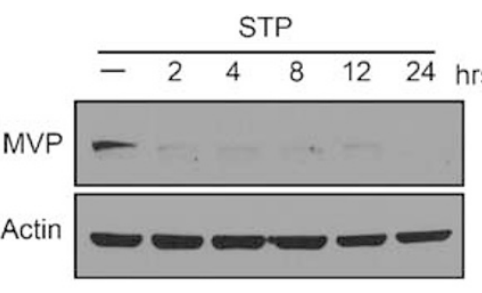
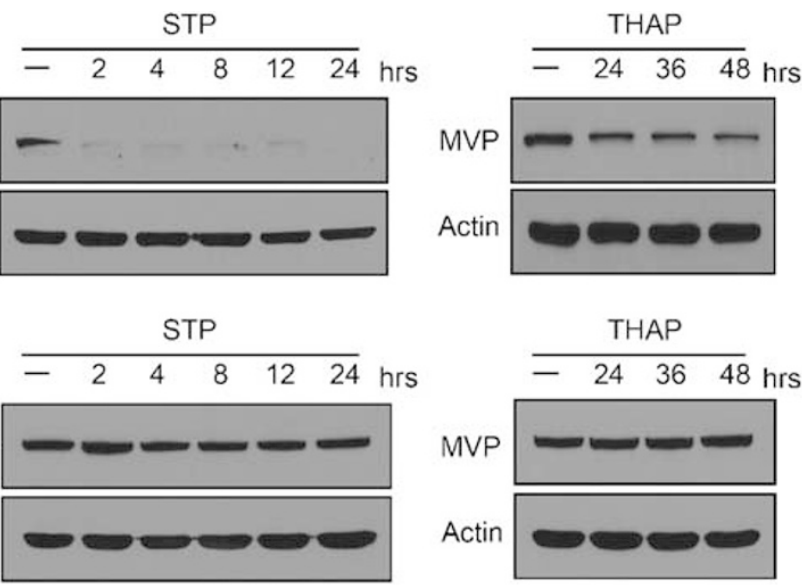

Actin
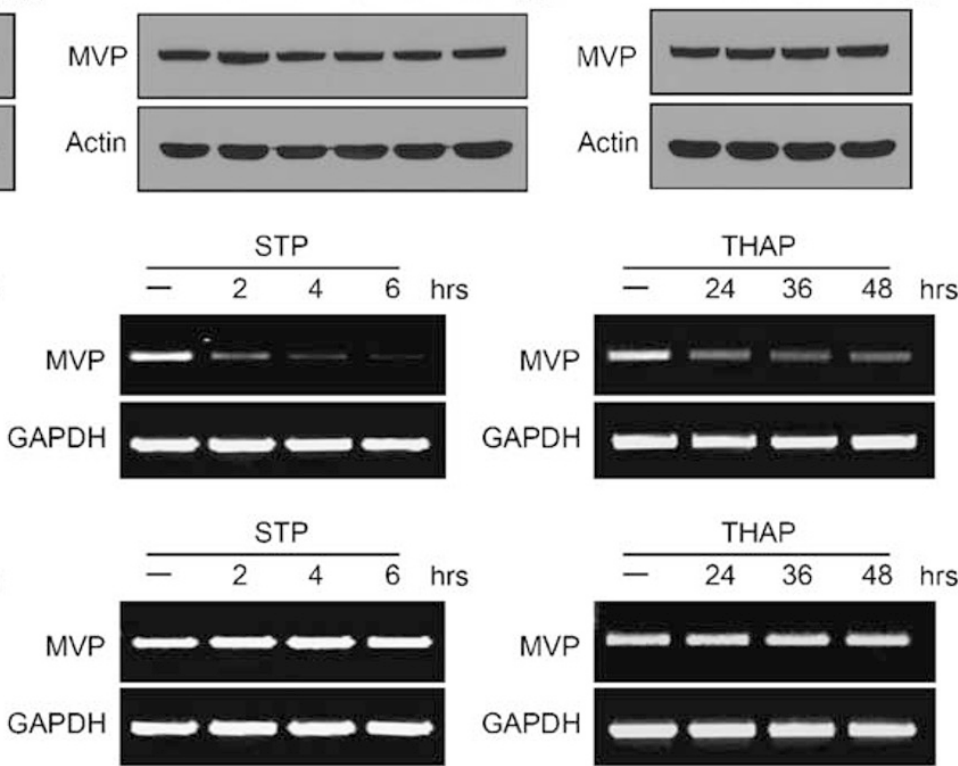

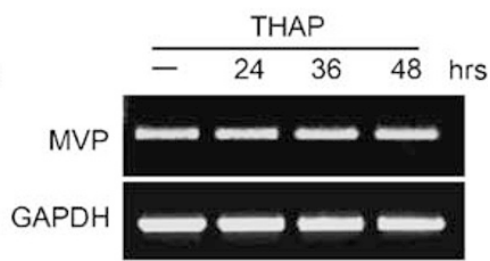

Figure 2 Levels of major vault protein (MVP) in $\mathrm{H}_{2} \mathrm{O}_{2}$, staurosporine or thapsigargin-treated young and senescent human diploid fibroblast (HDFs). Young (a, c) and senescent HDFs $(\mathbf{b}, \mathbf{d})$ were treated with $1.5 \mathrm{mM} \mathrm{H}_{2} \mathrm{O}_{2}, 100 \mathrm{nM}$ staurosporine or $100 \mathrm{nM}$ thapsigargin for the indicated times. Cells were then harvested. Protein and mRNA expression levels of MVP were determined by western blotting using anti-MVP antibody (a, b) and RT-PCR using specific MVP primer (c, d). Actin and GAPDH are loading controls. STP, staurosporine; THAP, thapsigargin

$\mathrm{H}_{2} \mathrm{O}_{2}$ or thapsigargin treatment in young HDFs but was not changed by staurosporine. In senescent HDFs, we found that localization of MVP is increased in cytoplasm by only thapsigargin treatment. These changes of subcellular localization during cell death need further study.

Increased apoptotic sensitivity in senescent HDFs following reduction of MVP. To examine the role of MVP in the apoptotic resistance of senescent HDFs, we downregulated MVP expression in these cells using MVP. specific small-interfering RNA (siRNA). We transfected senescent HDFs with three different MVP-specific siRNAs (nos. 1, 2 and 3) and a control siRNA. As can be seen in Figures $3 a$ and $b$, transfection with MVP-specific siRNAs resulted in a significant reduction in MVP in $72 \mathrm{~h}$. Morphological changes were noticed in MVP downregulated senescent HDFs following the three apoptotic stresses, and these included cellular exfoliation and drift in culture medium, indicating increased induction of apoptosis (Figure 4a). 3-(4,5-Dimethylthiazol-2-yl)-2,5-diphenyltetrazolium bromide (MTT) assays confirmed that MVP siRNA-transfected a
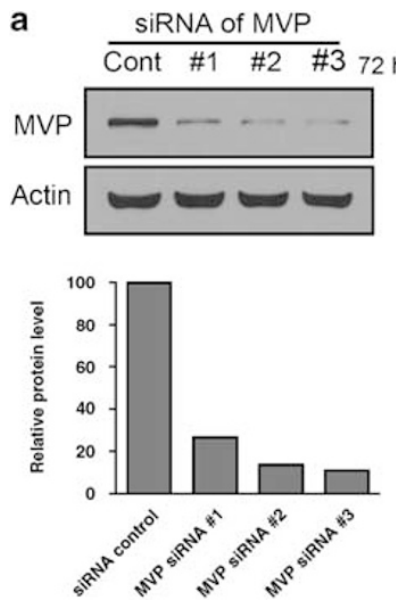

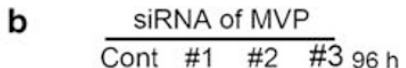
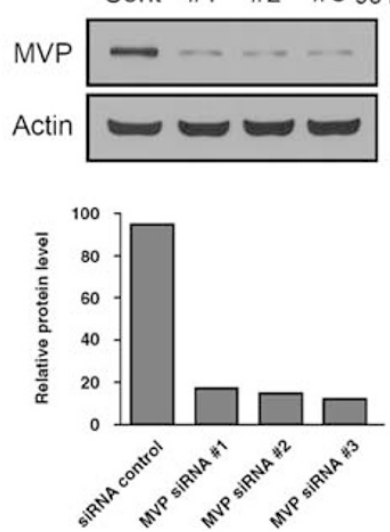

Figure 3 Downregulation of major vault protein (MVP) in senescent human diploid fibroblast (HDFs). Senescent HDFs were transfected with three different small-interfering RNAs (siRNAs) of MVP and a control siRNA as described in Materials and Methods using an Oligofectamine reagent. After $72 \mathrm{~h}(\mathbf{a})$ and $96 \mathrm{~h}(\mathrm{~b})$, cells were harvested. Protein expression of MVP was analyzed by western blotting using an anti-MVP antibody. Cont, control siRNA 
a

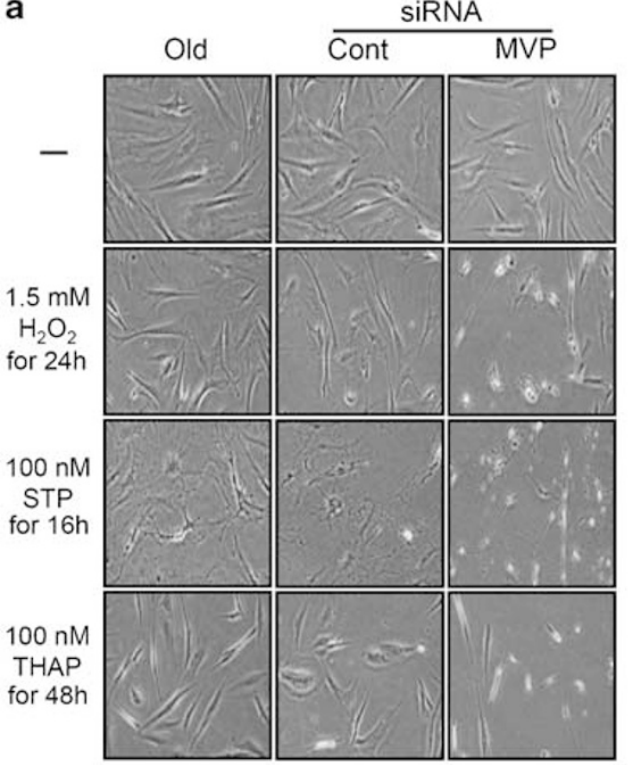

C
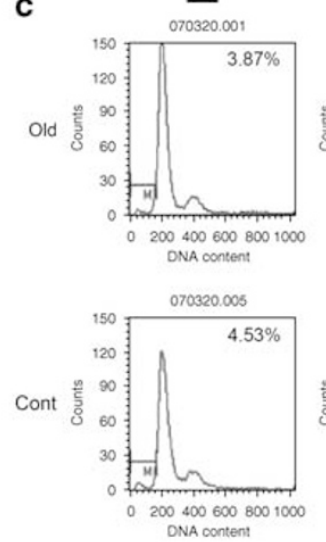

DNA conter

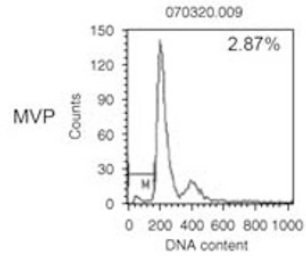

d

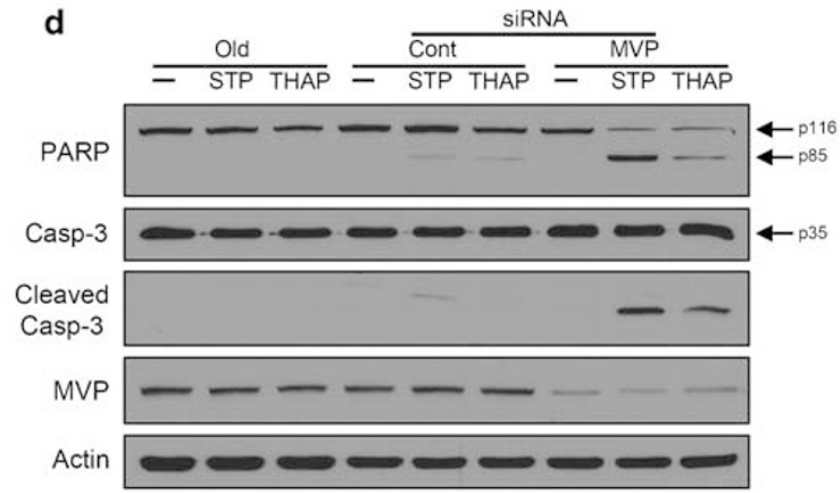

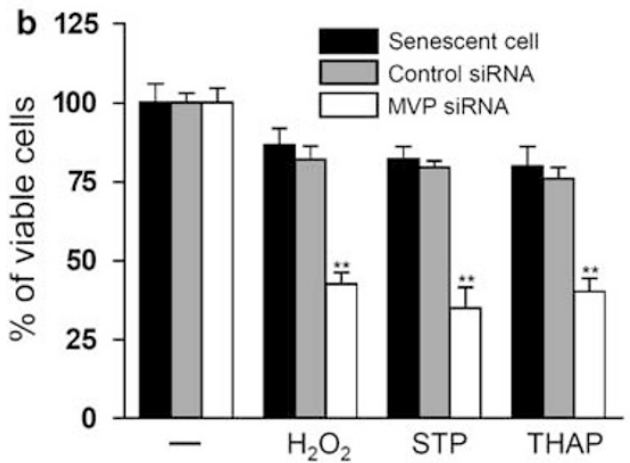
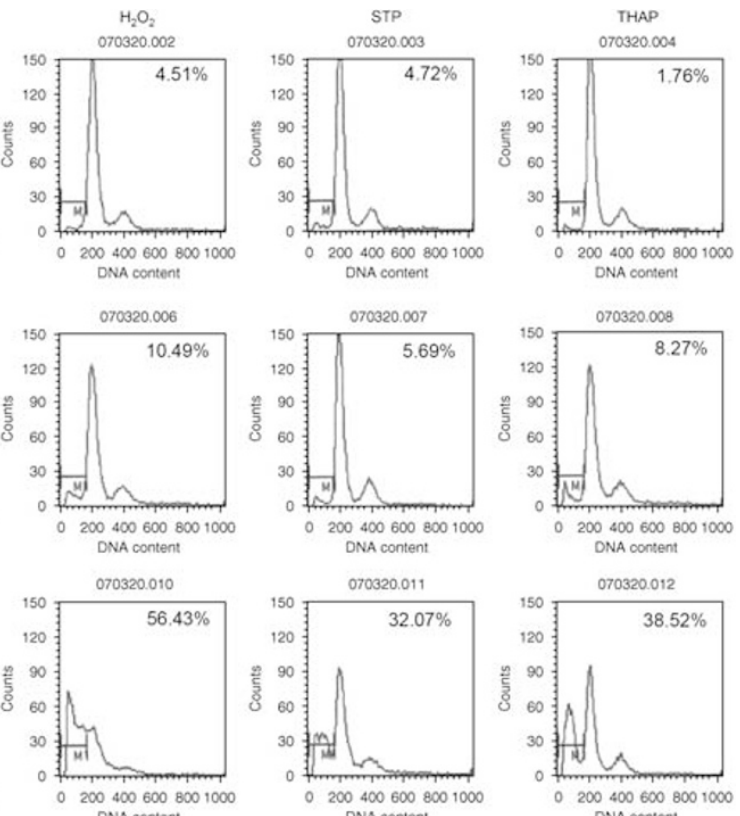

DNA content

Figure 4 Knockdown of endogenous major vault protein (MVP) sensitizes senescent human diploid fibroblast (HDFs) to $\mathrm{H}_{2} \mathrm{O}_{2}$, staurosporine or thapsigargin-induced cell death. Senescent HDFs were transfected with a specific small-interfering RNA (siRNA) no. 3 of MVP and control siRNA of GL2 luciferase, an siRNA directed against the firefly luciferase, by used Oligofectamine reagent. After $72 \mathrm{~h}$, cells were harvested. (a) Morphologies of senescent HDFs after MVP downregulation were determined by light microscopy. (b) 3-(4,5-Dimethylthiazol-2-yl)-2,5-diphenyltetrazolium bromide (MTT) assay. After transfecting MVP-specific siRNA for $72 \mathrm{~h}$, cells were treated with $1.5 \mathrm{mM}$ $\mathrm{H}_{2} \mathrm{O}_{2}, 100 \mathrm{nM}$ staurosporine or $100 \mathrm{nM}$ thapsigargin for 24,16 and $48 \mathrm{~h}$, respectively. Error bars represent the standard deviations of the means. Significance was tested by ANOVA followed by a Dunnett's post-test to compare the drug-treated group versus the control group. A double asterisk ${ }^{\star *} P<0.01$. (c) Senescent or control and MVP siRNAtransfected HDFs were treated with $1.5 \mathrm{mM} \mathrm{H}_{2} \mathrm{O}_{2}, 100 \mathrm{nM}$ staurosporine or $100 \mathrm{nM}$ thapsigargin for 24,16 and $48 \mathrm{~h}$, respectively. Cells were harvested by trypsinization and then stained with propidium iodide (PI). PI staining was determined by flow cytometry. (d) Senescent or control and MVP siRNA-transfected HDFs were treated with $100 \mathrm{nM}$ staurosporine or $100 \mathrm{nM}$ thapsigargin for 16 and $48 \mathrm{~h}$, respectively. Cells were harvested. Poly(ADP-ribose)polymerase (PARP) cleavage and caspase-3 activation were analyzed by western blotting using anti-PARP or anti-caspase-3 antibodies. Actin is loading control. STP, staurosporine; THAP, thapsigargin; Old, senescent HDFs; Cont, control siRNA-transfected senescent HDFs; MVP, MVP siRNA-transfected senescent HDFs; Casp-3, caspase-3

senescent HDFs are more sensitive to the apoptotic stresses (Figure 4b). Flow cytometric analysis showed significant accumulation of subploid cells, the so-called sub-G ${ }_{1}$ peak, in the MVP downregulated stressed senescent HDFs (Figure 4c). Proteolytic cleavage of pro-caspase-3 into its active form, a $17 \mathrm{kDa}$ fragment and of $116 \mathrm{kDa}$ PARP protein into a $85 \mathrm{kDa}$ fragment was observed (Figure 4d), confirming the increased apoptosis of MVP siRNA-transfected senescent HDFs after treatment with staurosporine and thapsigargin. $^{28}$

Modulation of Bcl-2 expression by MVP by JNK pathway. Bcl-2, which was previously shown by us is important in regulating the resistance of senescent HDFs to a variety of apoptotic stresses, ${ }^{27}$ was significantly reduced in MVP downregulated senescent HDFs, whereas Bax, a proapoptotic factor, and $\mathrm{Bcl}-\mathrm{xl}$, an antiapoptotic factor changed little (Figures $5 a$ and $b$ ). We also tracked the proapoptotic BH3-only proteins (BIM, PUMA, BAD, BIK) and the proapoptotic BAX/BAK family protein (BAK) in MVP downregulated senescent HDFs (Supplementary Figure 4) and found that $\mathrm{BH} 3-o n l y$ proteins and Bak was not changed by MVP siRNA. Studies by others demonstrated that the expression of Fos, Jun and $\mathrm{Bcl}-2$ gene families are modified during programmed death of skin cells ${ }^{29}$ and that different $\mathrm{AP}-1$ complexes are involved in the regulation of $\mathrm{Bcl}-2$ gene 
a

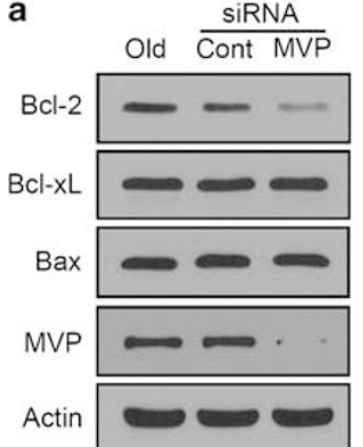

b

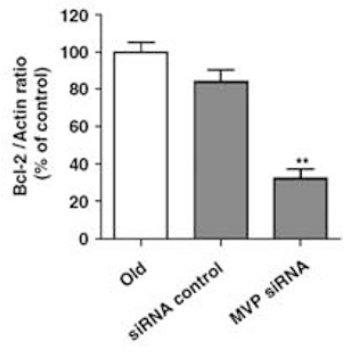

Figure 5 Knockdown of major vault protein (MVP) downregulates B-cell lymphoma protein-2 (Bcl-2) expression. (a) Senescent human diploid fibroblast (HDFs) were transfected with the small-interfering RNA (siRNA) of MVP and control. After $96 \mathrm{~h}$, cells were harvested. Whole-cell lysates were extracted and $40 \mu \mathrm{g}$ of total protein were analyzed for Bcl-2, Bcl-xl and Bax by western blotting. Actin was used as a loading control. (b) The quantitative graph of downregulated Bcl-2. The results shown are representative of three independent experiments; the histograms represent the average and the error bars represent the standard deviation of the means. Significance was tested by ANOVA followed by a Dunnett's post-test to compare the drug-treated group versus the control group. A double asterisk ${ }^{* *} P<0.01$. Old, senescent HDFs; Cont, control siRNA-transfected senescent HDFs; MVP, MVP siRNA-transfected senescent HDFs

expression. ${ }^{30}$ Moreover, MVP negatively regulates c-Jun levels and AP-1 transcription activity. ${ }^{31}$ Therefore, to understand the role of MVP in the expression of $\mathrm{Bcl}-2$, we examined MAP kinase pathway and c-jun accumulation. We observed that phosphorylation of c-Jun $\mathrm{NH}(2)$-terminal kinase (JNK) is up regulated and that accumulation of $c$-jun is significantly enhanced in MVP downregulated senescent HDFs without any significant changes in p-Erk and p-p38 (Figures $6 a$ and $b$ ). To investigate the effects of JNK inhibition on survival and MVP levels in young and senescent HDFs, we treated young and senescent HDFs with $40 \mu \mathrm{M}$ SP600125 (Supplementary Figure 5). There were no significant differences in the survival and MVP levels between the young and senescent HDFs subjected to SP600125. Next, to elucidate whether JNK activation is affecting the reduction of $\mathrm{Bcl}-2$ in senescent HDFs, we treated MVP siRNA-transfected HDFs with JNK MAP kinase specific inhibitor, SP600125, and found that the level of Bcl-2 protein was restored (Figure $6 \mathrm{c}$ ). These results suggest that MVP modulates $\mathrm{Bcl}-2$ gene by negative regulation of the JNK C-jun pathway.

\section{Discussion}

In this study, we examined whether MVP contributes to apoptosis resistance of senescent HDFs and how MVP regulates cell survival signaling. We found that MVP levels increase significantly in senescent HDFs and organs, such as the heart, liver, spleen and lungs of aged-mice (Figures 1a-e). This suggests a possible cause and effect relationship between the resistance to apoptosis exhibited by senescent cells and their high content of MVP. In contrast to previous studies that showed that the majority of MVP resides in the cytoplasm and that no more than $5 \%$ of MVP is localized to the nucleus, ${ }^{15,16}$ we observed that the MVP is equally localized in both the cytoplasm and nucleus (Figures $1 \mathrm{f}$ and $\mathrm{g}$ ). Moreover,

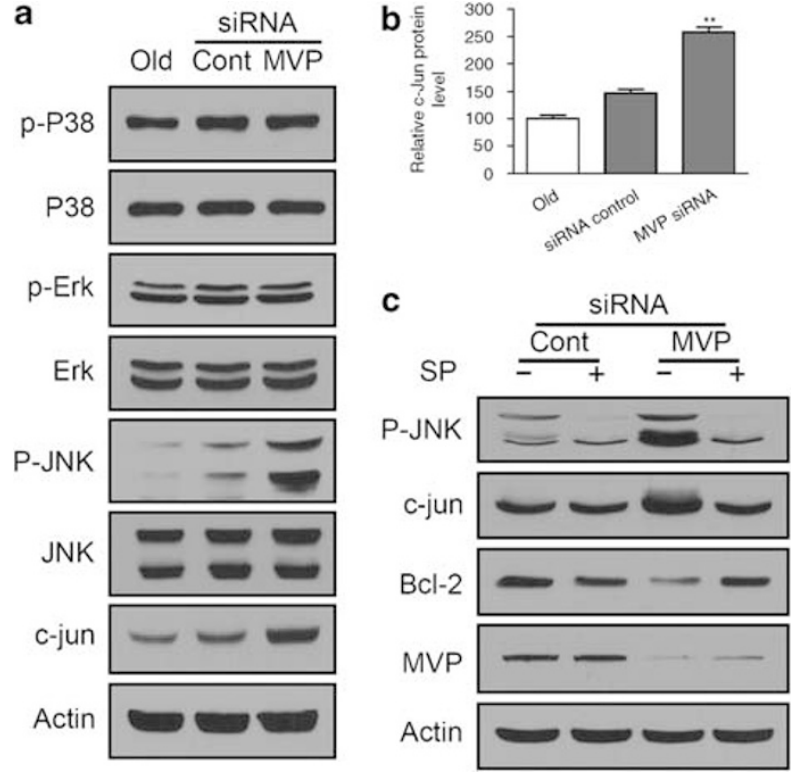

Figure 6 Major vault protein (MVP) regulates B-cell lymphoma protein-2 (Bcl-2) by negative regulation of the c-Jun $\mathrm{NH}(2)$-terminal kinase (JNK) pathway. (a) Senescent human diploid fibroblast (HDFs) were transfected with the smallinterfering RNA (siRNA) of MVP and control. After $96 \mathrm{~h}$, the cells lysates were immunoblotted with anti-p-Erk, anti-p-P38, anti-P-JNK and anti-c-jun antibody. The blots were reprobed with antibody against actin to confirm equal protein loading. (b) The quantitative graph of downregulated Bcl-2. The results shown are representative of three independent experiments; the histograms represent the average and the error bars represent the standard deviation of the means. Significance was tested by ANOVA followed by a Dunnett's post-test to compare the drug-treated group versus the control group. A double asterisk ${ }^{\star \star} P<0.01$. (c) Senescent HDFs were pretreated for $1 \mathrm{~h}$ with $10 \mu \mathrm{M}$ of SP600125 (JNK MAP kinase inhibitor) and then treated with the siRNA of MVP and SP600125. The medium was then replaced daily with fresh serum-free media containing JNK inhibitor. After $96 \mathrm{~h}$, the cells were harvested. Cell lysates were analyzed by western blotting with the indicated antibodies. SP, SP600125

in the case of $253 \mathrm{~J}$ cells, it was reported that more MVP was detected in the nucleus than in cytosol. ${ }^{22}$ These results suggest that MVP localization might depend on cell status or cell type. Clearly, the detailed mechanism of MVP translocation from the cytoplasm to the nucleus in young and senescent HDFs should be further elucidated.

A number of studies have demonstrated that MVP expression can be induced in several tumor cell lines by a variety of differentiating agents and cytotoxic drugs. ${ }^{12-14,32}$ However, a reduction of MVP mRNA and protein was detected in two human colon carcinoma cell lines treated with TNF- $\alpha .{ }^{26}$ In this study, we observed that the levels of MVP protein and mRNA were downregulated only in young $\mathrm{HDF}$, but not in senescent $\mathrm{HDFs}$, treated with apoptosis-inducing agents such as $\mathrm{H}_{2} \mathrm{O}_{2}$, staurosporine and thapsigargin (Figure 2), suggesting age dependency of MVP response. Human MVP gene contains transcription factor-binding sites for p53, STAT1, Sp1 and MyoD, ${ }^{32,33}$ and transcription factors including STAT1, YB-1 and $\mathrm{Sp}-1$ are involved in the regulation of MVP in different cell types. $^{14,32,34}$ Interestingly, we observed that the basal and phosphorylation status of p53 are either increased or decreased in specific agonist-induced apoptosis of young HDFs, but the status of other transcription factors for MVP such as STAT1, Sp1 and MyoD did not change (data not 
shown). How p53 regulates MVP expression in an agonistspecific manner remains to be clarified.

To determine whether the high level of MVP contributes to the resistance of senescent cells to apoptosis, we examined the sensitivity to apoptosis of MVP downregulated senescent HDFs (Figure 3). As shown in Figure 4, MVP downregulated senescent HDFs showed increased sensitivity to a variety of apoptotic agonists such as $\mathrm{H}_{2} \mathrm{O}_{2}$, staurosporine and thapsigargin. To investigate the effect of MVP siRNA on young HDFs, we transfected young HDFs with various doses of MVP-specific siRNA for $72 \mathrm{~h}$ and found a dose-dependent downregulation of MVP (Supplementary Figure 6a). MTT assays revealed that the survival rate of MVP downregulated young HDFs decreased to $15-20 \%$ after staurosporine and thapsigargin treatments, with no detectable change in the survival rate after $\mathrm{H}_{2} \mathrm{O}_{2}$ treatment (Supplementary Figure $6 b$ ). To further dissect the mechanism of stress-induced cell death, we analyzed DNA fragmentation by fluorescence-activated cell sorter (FACS). As shown in Supplementary Figure $6 c$, the sub- $G_{1} / G_{0}$ population increased by $10-15 \%$ in staurosporine and thapsigargin-treated MVP downregulated young HDFs but not in $\mathrm{H}_{2} \mathrm{O}_{2}$-treated MVP downregulated young HDFs. Next, assessing the Bcl-2 family proteins and MAP kinases, we found that $\mathrm{Bcl}-\mathrm{xl}$ protein was reduced (Supplementary Figure 6d), but the phosphorylation of MAP kinases and expression of c-jun did not change (Supplementary Figure 6e) in MVP downregulated young HDFs. Furthermore, we found that the overexpression of MVP in young HDFs leads to resistance to apoptosis-inducing agents and increase in $\mathrm{Bcl}-2$ protein (Supplementary Figure 7). How MVP downregulation decreases the expression of $\mathrm{Bcl}-\mathrm{xl}$ in young HDFs requires further study.

On the basis of this study, we tentatively conclude that MVP is closely associated with age dependence of apoptosis resistance of HDFs. Several recent studies have suggested that MVP is involved in cell survival following stress or damage, ${ }^{34,35}$ but apparently plays no role in development as MVP knockout mice exhibit no discernible developmental abnormalities. ${ }^{35}$

We have recently shown that increased levels of $\mathrm{Bcl}-2$ contribute to apoptotic resistance in senescent HDFs. ${ }^{27}$ To understand the mechanism by which MVP promotes the survival of senescent HDFs, we monitored the level of Bcl-2 protein in MVP siRNA-transfected senescent HDFs and found that $\mathrm{BCl}-2$ is significantly reduced in MVP downregulated senescent HDFs (Figure 5).

Signaling molecules, such as extracellular-regulated kinase (Erk), JNK and p38, are reportedly involved in the apoptotic process. ${ }^{36}$ It has also been reported that activation of the JNK pathway is required for stress-induced apoptotic processes. ${ }^{37}$ A major target of the JNK pathway is the transcription factor cJun, a member of the AP-1 complexes. ${ }^{38}$ It is well known that phosphorylation of the $\mathrm{NH}(2)$-terminal transactivation domains of c-Jun correlates well with increased transactivating activity and that JNK can phosphorylate the c-Jun transactivating domain at Ser-63 and Ser-73. ${ }^{39,40}$ Expressions of Fos, Jun and Bcl-2 family genes are modulated during programmed death of skin cells. ${ }^{29}$ Different AP-1 complexes regulate $\mathrm{BCl}-2$ gene expression ${ }^{30}$ and MVP suppresses c-Junmediated AP-1 transcription. ${ }^{31}$ To explain the mode of regulation of $\mathrm{Bcl}-2$ by MVP, we examined the phosphorylation status of MAP kinases and c-Jun accumulation. As shown in Figures $6 a$ and $b$, both JNK phosphorylation and c-Jun were enhanced in MVP siRNA-transfected senescent HDFs, whereas the phosphorylation status of Erk and p38 was not changed, which suggests the involvement of the JNK pathway in MVP function. To determine whether MVP regulates $\mathrm{Bcl}-2$ gene through JNK c-Jun-mediated pathway, we treated MVP siRNA-transfected senescent HDFs with SP600125, a specific JNK inhibitor, and found that this resulted in the restoration of $\mathrm{Bcl}-2$ protein (Figure $6 \mathrm{c}$ ). On the basis of these results, we conclude that MVP modulates $\mathrm{Bcl}-2$ gene expression through negative regulation of the JNK c-Junmediated pathway.

Next, we questioned how MVP knockdown decreases phosphorylation of JNK in senescent HDFs. We examined, by immunoblotting MVP complexes with JNK and p-JNK antibodies, whether JNK and p-JNK interacted with MVP in young and senescent HDFs. We did not observe any direct association of either JNK or p-JNK with MVP (data not shown). MVP could interact with the activated forms of the extracellular-regulated kinaseErks in response to EGF, suggesting that MVP might function as a novel scaffold protein for Erk. ${ }^{20}$ However, the absence of interaction between $\mathrm{p}$-JNK and MVP might suggest that the mode of action of MVP in the JNK pathway might be different.

This study is the first to propose that MVP prolongs cell survival by promoting resistance to apoptosis in an agedependent manner. We have shown in this work that (1) MVP is increased in senescent HDFs and old tissues; (2) MVP protein and mRNA are downregulated in response to apoptotic stress, time dependently in young HDFs but not in senescent HDFs; and (3) knocking down MVP expression in senescent HDFs with siRNA increases their sensitivity to apoptosis. We also propose that MVP modulates the sensitivity of senescent HDFs to apoptosis by increasing the level of the antiapoptotic protein, $\mathrm{Bcl}-2$, by negative regulation of JNK MAP kinase pathway. We recognize that the relationship with efflux activity and efficiency of drug clearing needs to be confirmed. The mechanisms underlying the induction of apoptosis resistance by MVP in senescent cells proposed in this study provide a possible clue to understanding the development of multidrug resistance of cancer cells.

\section{Materials and Methods}

Reagents. The sources of various reagents and materials were as follows: DNase I (Roche Diagnostics, Mannheim, Germany) monoclonal antibody against actin was from Santa Cruz Biotechnology Inc.; Polyclonal antibodies against p-Erk, p-P38, P-JNK, c-jun, PARP, caspase-3, Bcl-2, Bcl-xl, Bax, Bim, Bad, Puma, Bik and Bak were from Cell Signaling Technologies Inc.; Monoclonal antibody against MVP was from Transduction Laboratories (Lexington, KY, USA); Staurosporine was from Calbiochem (La Jolla, CA, USA). Hydrogen peroxide, thapsigargin, propidium iodide and MTT were from Sigma Chemical Co. (St Louis, MO, USA). Alexa Fluor 488 goat anti-mouse immunoglobulin $\mathrm{G}$ was from Molecular Probes. Secondary horseradish peroxidase-conjugated anti-rabbit and anti-mouse antibodies were from Zymed Laboratories Inc., and chemiluminescent detection systems were from Pierce. All other biochemical reagents were from Sigma or Invitrogen. TwinChip ${ }^{\mathrm{TM}}$ Human-8K was provided by Digital-Genomics Inc. (Seoul, Republic of Korea). SiRNA were from Dharmacon Research (Lafayette, CO, USA) as duplex-ready stable 2'-ACE protected form HDFs. HDFs were isolated from human foreskins. 
Cell studies. The primary culture of normal HDF was isolated from the foreskin of a 4-year-old boy. HDFs were kept in $100 \mathrm{~mm}$ tissue culture dishes in Dulbecco's modified Eagle's medium supplemented with $10 \%$ fetal bovine serum, $100 \mathrm{U} / \mathrm{ml}$ penicillin and $100 \mu \mathrm{g} / \mathrm{ml}$ streptomycin, maintained in $5 \% \mathrm{CO}_{2}$ in a humid incubator at $37^{\circ} \mathrm{C}$. Cells were cultured as described by Ryu et al. ${ }^{27}$ Cellular senescence was confirmed using an senescence-associated $\beta$-galactosidase activity assay. HDFs were grown to $70 \%$ confluence and then treated with $1.5 \mathrm{mM} \mathrm{H}_{2} \mathrm{O}_{2}, 100 \mathrm{nM}$ staurosporine or $100 \mathrm{nM}$ thapsigargin in serum-free media for the times indicated in 'Results'.

RNA preparation and cDNA microarray analysis. Total RNA was prepared from young and senescent HDFs using TRIzol reagents (Invitrogen) according to the manufacturer's instructions. RNA purity was determined by measuring absorbance at $260 / 280 \mathrm{~nm}$ in a spectrophotometer (Beckman, USA). RNA samples from young and senescent HDFs were used to make cDNAs labeled with Cy5 and Cy3, respectively. Microarray experiments were performed according to the manufacturer's standard protocol.

Semiquantitative RT-PCR. Extracted RNA was treated with DNase I and reverse transcribed to single-stranded cDNAs using oligo(dT) 12-18 primer with Superscript II reverse transcriptase (invitrogen). Appropriate dilutions of each single-stranded CDNA were prepared for subsequent PCR amplification by monitoring the GAPDH gene as a quantitative control. Primer sequences were as follows:

$5^{\prime}$-CATCATTCGCACTGCTGTCT-3' and $5^{\prime}$-CAGCTCCAAAAGTTCCTTGC- $3^{\prime}$ for MVP.

$5^{\prime}$-ACCACAGTCCATGCCATCAC- $3^{\prime}$ and $5^{\prime}$-TCCACCACCCTGTTGCTGTA- $3^{\prime}$ for GAPDH.

RT-PCR was performed using the following conditions for MVP gene: $42^{\circ} \mathrm{C}$ for $1 \mathrm{~h}, 95^{\circ} \mathrm{C}$ for $10 \mathrm{~min}, 29$ cycles of (1) $94^{\circ} \mathrm{C}$ for $30 \mathrm{~s}$, (2) $52^{\circ} \mathrm{C}$ for $30 \mathrm{~s}$, (3) $72^{\circ} \mathrm{C}$ for $1 \mathrm{~min}$ and $72^{\circ} \mathrm{C}$ for $10 \mathrm{~min}$. Samples were analyzed by gel electrophoresis and bands were revealed by staining gels with ethidium bromide.

Animals and homogenization of tissues. C57B//6J male mice of two different age groups, young (4 months) and old (24 months), kept under standard laboratory conditions were used. The mice were killed by cervical dislocation. Hearts, spleens, lungs, livers, kidneys and skeletal muscles were frozen in liquid nitrogen and kept at $-80^{\circ} \mathrm{C}$ until further use. Frozen tissues were homogenized by 10-15 strokes each with a polytron tissue homogenizer and a teflon-glass homogenizer (GlasCol, Terre Haute, IN, USA) at high speed and sonicated with a VCX 400 sonication machine (Sonics \& Materials Inc., CT, USA) in homogenation buffer $(10 \mathrm{mM}$ Tris- $\mathrm{HCl}$, pH 7.6, $5 \mathrm{mM}$ EDTA, $5 \mathrm{mM}$ EGTA, $0.5 \mu \mathrm{g} / \mathrm{ml}$ antipain, $0.1 \mathrm{mM}$ PMSF, $140 \mu \mathrm{g} / \mathrm{ml}$ trypsin inhibitor). The homogenate was centrifuged at $16000 \times g$ for $15 \mathrm{~min}$ and the supernatant was collected and used in the subsequent experiments.

Immunoblot analysis. Cells and tissues were solubilized with a lysis buffer containing $50 \mathrm{mM}$, Tris pH 7.4, $150 \mathrm{mM} \mathrm{NaCl}, 1 \mathrm{mM}$ EDTA, pH 8.0, 1\% SDS, protease inhibitor cocktail (Roche), $1 \mathrm{mM}$ PMSF, $1 \mathrm{mM} \mathrm{NaF}$ and $1 \mathrm{mM}$ sodium orthovanadate. Protein contents were determined using Bradford assay. Protein $(40 \mu \mathrm{g})$ of each sample was resolved by SDS-PAGE, transferred onto nitrocellulose membranes (Schleicher \& Schuell Bioscience Inc.) and blocked with TBS containing Tween-20 in $2.5 \%$ nonfat dry milk. The membranes were incubated with the primary antibodies at $4^{\circ} \mathrm{C}$ overnight. Secondary antibodies were added for $1 \mathrm{~h}$ at RT. The antibody-antigen complexes were detected using the ECL detection system (Pierce).

Northern analysis. About $15 \mu \mathrm{g}$ of total RNA was dissolved in RNA loading buffer ( $45 \mathrm{mM}$ Tris borate, $1 \mathrm{mM}$ EDTA, $90 \%$ (v/v) formaldehyde) and separated by electrophoresis on a $10 \%$ polyacrylamide gel containing $8 \mathrm{M}$ urea. The separated RNA was transferred to a Zeta-probe membrane using a semi-dry blotting method. In brief, RNAs were electroblotted at $70 \mathrm{~V}$ for $15 \mathrm{~min}$ followed by $100 \mathrm{~V}$ for $45 \mathrm{~min}$ in TAE buffer ( $40 \mathrm{mM}$ Tris acetate, $1 \mathrm{mM}$ EDTA). The membrane was then crosslinked by UV $\left(1.5 \mathrm{~J} / \mathrm{cm}^{2}\right)$ and prehybridized in Church buffer $(0.5 \mathrm{M}$ sodium phosphate $(\mathrm{pH}$ $7.2), 7 \%(\mathrm{w} / \mathrm{v})$ SDS, $1 \mathrm{mM}$ EDTA $(\mathrm{pH} 7.0))$ at $68^{\circ} \mathrm{C}$ for $2 \mathrm{~h}$. The following oligonucleotide probes were used: HVG1, 5'-GCTTGTTTCAATTAAAGAACTG TCG; HVG2, 5'-AGGTGGTTACAATGTACTCGAAG; HVG3, 5'-GAGGTGGTTT GATGACACGCGAAG and HVG4, 5'-CCTAACCATGGAAAGCATTGTCG. five S rRNA (5'-TCTCCCATCCAAGTACTAACCAGGCC) were used as a control for equal loading. The probes were end-labeled with [ $\gamma^{32}$ P]ATP. Hybridizations were performed at $68^{\circ} \mathrm{C}$ in Church buffer overnight. Subsequently, the membranes were washed twice at room temperature in $2 \times$ SSC, $0.1 \%$ SDS $(20 \times$ SSC: $3 \mathrm{M}$ trisodium citrate dehydrate, $\mathrm{pH} 8$ ) and thrice in $5 \times$ SSC, $0.1 \%$ SDS for 10 min at $68^{\circ} \mathrm{C}$. Blots were exposed to Agfa X-ray film at $-70^{\circ} \mathrm{C}$.

Subcellular fractionation. To prepare nuclear and cytosol extracts, $6 \times 10^{6}$ cells were harvested by trypsin, washed three times with phosphate-buffered saline and resuspended to $6 \times 10^{6}$ cells per $\mathrm{ml}$ in TM-2 buffer containing $10 \mathrm{mM}$ Tris, $\mathrm{pH}$ $7.4,2 \mathrm{mM} \mathrm{MgCl}, 1 \mathrm{mM}$ phenylmethylsulfonyl fluoride and protease inhibitors. Resuspended cells were incubated at room temperature for $1 \mathrm{~min}$ and then transferred into a tube in ice for $5 \mathrm{~min}$ with Triton X-100 added to a final concentration of $0.5 \%$ and incubated on ice for $10 \mathrm{~min}$. Cell lysates were separated by 70-80 passages through a 26-gauge needle. The nuclei were isolated from the cytosol by centrifugation at 6000 r.p.m. at $4{ }^{\circ} \mathrm{C}$ for $10 \mathrm{~min}$. Isolated nuclei were washed with TM-2 buffer and resuspended in a nuclear extraction buffer containing $20 \mathrm{mM}$ of Hepes, pH 7.9, $0.42 \mathrm{M} \mathrm{NaCl}, 1.5 \mathrm{mM} \mathrm{MgCl}_{2}, 25 \%$ (v/v) glycerol, $0.2 \mathrm{mM}$ EDTA, $0.5 \mathrm{mM}$ dithiothreitol and protease inhibitors. Resuspended nuclei were incubated on ice for $30 \mathrm{~min}$ with occasional shaking and sonicated to extract the nuclear proteins and finally were spun down in a microcentrifuge for $5 \mathrm{~min}$

Immunofluorescence staining. Cells were plated on 24-well culture plates with coverslips. The cells were washed three times with ice-cold phosphate-buffered saline (PBS) and fixed in $4 \%$ paraformaldehyde in PBS for $15 \mathrm{~min}$, and then permeabilized with $0.5 \%$ Triton X-100 in PBS for 10 min. Nonspecific protein-binding sites were saturated with $2 \%$ BSA in PBS for $30 \mathrm{~min}$. The cells were incubated with monoclonal antibody against MVP (1:100 dilution) overnight in cold and then washed three times with ice-cold PBS. Cells were incubated with FITC-conjugated secondary antibody for $30 \mathrm{~min}$. Nuclei were then fluorescently labeled with DAPI. After washing four times with ice-cold PBS, coverslips were mounted on glass slides by mounting medium. Fluorescent images were then obtained using a confocal microscope.

Analysis of apoptosis by cell cycle. After treatment with $\mathrm{H}_{2} \mathrm{O}_{2}$, staurosporine and thapsigargin, the suspended and adherent cells were harvested by centrifugation and treatment with trypsin-EDTA, respectively, and then washed twice with PBS, and fixed with ice-cold $70 \%$ ethanol. Cells were pelleted by centrifugation for $5 \mathrm{~min}$ at 3000 r.p.m., $4^{\circ} \mathrm{C}$, and the supernatant was discarded. Cells were then resuspended in a propidium iodide solution $(50 \mu \mathrm{g} / \mathrm{ml}$ in PBS) that contained $50 \mu \mathrm{g} / \mathrm{ml}$ RNase A and incubated in the dark at room temperature for $20 \mathrm{~min}$. The sub- $\mathrm{G}_{1}$ content of the cells was then analyzed using the FACScan immunocytometry system.

RNA interference and transfection. Three regions of MVP mRNA were targeted for RNA interference. The target sequences were as follows: MVP no. 1: 5'-TAGGAGTCACCATGGCAAC-3'; MVP no. 2: 5'-AAGAGTATGTGCCATCTG CCA-3'; MVP no. 3: 5'-ACATCCGGCAGGACAATGA-3'. A synthetic siRNA directed against the firefly luciferase mRNA sequence $5^{\prime}$-AACGUACGCGG AAUACUUCGA- $3^{\prime}$ was used as a negative control. The siRNAs were purchased from Dharmacon Research as duplex-ready stable $2^{\prime}$-ACE protected form. The transfection of siRNA duplexes was performed as described previously. ${ }^{27} \mathrm{MVP}$-Flag was a generous gift from Dr. Kim EK (Department of Toxicology, College of Veterinary Medicine, GyeongSang National University, Gajwa-dong, Jinju-si, Gyeongsangnam-do, Korea). The plasmid DNA was transiently transfected into young HDFs by the use of Lipofectamine according to the manufacturer's protocol.

Acknowledgements. This work was generously supported by grants from the Aging and Apoptosis Research Center (R11-2002-097-05-001-0), the Research Program of Cancer - Aging from KOSEF, the Korea Research Foundation for Health Science and the SNU BK21 program from the Ministry of Education.

1. van Zon A, Mossink MH, Scheper RJ, Sonneveld P, Wiemer EA. The vault complex. Cell Mol Life Sci 2003; 60: 1828-1837.

2. Kedersha NL, Heuser JE, Chugani DC, Rome LH. Vaults. III. Vault ribonucleoprotein particles open into flower-like structures with octagonal symmetry. J Cell Biol 1991; 112: 225-235. 
3. Kedersha NL, Rome LH. Isolation and characterization of a novel ribonucleoprotein particle: large structures contain a single species of small RNA. J Cell Biol 1986; 103: 699-709.

4. van Zon A, Mossink MH, Schoester M, Scheffer GL, Scheper RJ, Sonneveld P et al. Structural domains of vault proteins: a role for the coiled coil domain in vault assembly. Biochem Biophys Res Commun 2002; 291: 535-541.

5. Schadendorf D, Makki A, Stahr C, van Dyck A, Wanner R, Scheffer GL et al. Membrane transport proteins associated with drug resistance expressed in human melanoma. Am J Pathol 1995; 147: 1545-1552.

6. Meijer GA, Schroeijers AB, Flens MJ, Meuwissen SG, van der Valk P, Baak JP et al. Increased expression of multidrug resistance related proteins Pgp MRP1, and LRP/MVP occurs early in colorectal carcinogenesis. J Clin Pathol 1999; 52: 450-454.

7. Berger W, Spiegl-Kreinecker S, Buchroithner J, Elbling L, Pirker C, Fischer J et al. Overexpression of the human major vault protein in astrocytic brain tumor cells. Int J Cancer 2001; 94: 377-382.

8. Hu Y, Stephen AG, Cao J, Tanzer LR, Slapak CA, Harrison SD et al. A very early induction of major vault protein accompanied by increased drug resistance in U-937 cells. Int J Cancer 2002; 97: 149-156.

9. Kickhoefer VA, Rajavel KS, Scheffer GL, Dalton WS, Scheper RJ, Rome LH. Vaults are up-regulated in multidrug-resistant cancer cell lines. J Biol Chem 1998; 273: 8971-8974.

10. Schroeijers AB, Reurs AW, Scheffer GL, Stam AG, de Jong MC, Rustemeyer T et al. Upregulation of drug resistance-related vaults during dendritic cell development. $J$ Immuno 2002; 168: 1572-1578.

11. Kitazono M, Sumizawa T, Takebayashi $Y$, Chen ZS, Furukawa T, Nagayama $S$ et al. Multidrug resistance and the lung resistance-related protein in human colon carcinoma SW-620 cells. J Natl Cancer Inst 1999; 91: 1647-1653.

12. Komarov PG, Shtil AA, Holian O, Tee L, Buckingham L, Mechetner EB et al. Activation of the LRP (lung resistance-related protein) gene by short-term exposure of human leukemia cells to phorbol ester and cytarabine. Oncol Res 1998; 10: 185-192.

13. Berger W, Elbling L, Micksche M. Expression of the major vault protein LRP in human nonsmall-cell lung cancer cells: activation by short-term exposure to antineoplastic drugs. Int J Cancer 2000; 88: 293-300.

14. Stein U, Bergmann S, Scheffer GL, Scheper RJ, Royer HD, Schlag PM et al. YB-1 facilitates basal and 5 -fluorouracil-inducible expression of the human major vault protein (MVP) gene. Oncogene 2005; 24: 3606-3618

15. Chugani DC, Rome LH, Kedersha NL. Evidence that vault ribonucleoprotein particles localize to the nuclear pore complex. J Cell Sci 1993; 106 (Part 1): 23-29.

16. Abbondanza C, Rossi V, Roscigno A, Gallo L, Belsito A, Piluso G et al. Interaction of vault particles with estrogen receptor in the MCF-7 breast cancer cell. J Cell Biol 1998; 141 1301-1310.

17. Chung JH, Ginn-Pease ME, Eng C. Phosphatase and tensin homologue deleted on chromosome 10 (PTEN) has nuclear localization signal-like sequences for nuclear import mediated by major vault protein. Cancer Res 2005; 65: 4108-4116.

18. Kowalski MP, Dubouix-Bourandy A, Bajmoczi M, Golan DE, Zaidi T, Coutinho-Sledge YS et al. Host resistance to lung infection mediated by major vault protein in epithelial cells. Science 2007; 317: 130-132.

19. Mrazek J, Kreutmayer SB, Grasser FA, Polacek N, Huttenhofer A. Subtractive hybridization identifies novel differentially expressed ncRNA species in EBV-infected human B cells. Nucleic Acids Res 2007; 35: e73.

20. Kolli S, Zito $\mathrm{Cl}$, Mossink MH, Wiemer EA, Bennett AM. The major vault protein is a nove substrate for the tyrosine phosphatase SHP-2 and scaffold protein in epidermal growth factor signaling. J Biol Chem 2004; 279: 29374-29385.
21. Yu Z, Fotouchi-Ardakani N, Wu L, Maoui M, Wang S, Banville D et al. PTEN associates with the vault particles in HeLa cells. J Biol Chem 2002; 277: 40247-40252.

22. Kim E, Lee S, Mian MF, Yun SU, Song M, Yi KS et al. Crosstalk between Src and major vault protein in epidermal growth factor-dependent cell signalling. FEBS J 2006; 273: 793-804.

23. Vasu SK, Rome LH. Dictyostelium vaults: disruption of the major proteins reveals growth and morphological defects and uncovers a new associated protein. J Biol Chem 1995; 270 : 16588-16594.

24. Slesina M, Inman EM, Rome LH, Volknandt W. Nuclear localization of the major vault protein in U373 cells. Cell Tissue Res 2005; 321: 97-104.

25. Emre N, Raval-Fernandes S, Kickhoefer VA, Rome LH. Analysis of MVP and VPARP promoters indicates a role for chromatin remodeling in the regulation of MVP. Biochim Biophys Acta 2004; 1678: 33-46.

26. Stein U, Walther W, Laurencot CM, Scheffer GL, Scheper RJ, Shoemaker RH. Tumor necrosis factor-alpha and expression of the multidrug resistance-associated genes LRP and MRP. J Natl Cancer Inst 1997; 89: 807-813.

27. Ryu SJ, Oh YS, Park SC. Failure of stress-induced downregulation of Bcl-2 contributes to apoptosis resistance in senescent human diploid fibroblasts. Cell Death Differ 2007; 14: 1020-1028.

28. Nicholson DW, Ali A, Thomberry NA, Vaillancourt JP, Ding CK, Gallant M et al. Identification and inhibition of the ICE/CED-3 protease necessary for mammalian apoptosis. Nature 1995; 376: 37-43.

29. Albarenque SM, Suzuki K, Shinozuka J, Nakayama H, Doi K. Kinetics of apoptosis-related genes mRNA expression in the dorsal skin of hypotrichotic WBN/ILA-ht rats after topical application of T-2 toxin. Exp Toxicol Pathol 2001; 52: 553-556.

30. Aubert N, Falluel-Morel A, Vaudry D, Xifro X, Rodriguez-Alvarez J, Fisch C et al. PACAP and $\mathrm{C} 2$-ceramide generate different AP-1 complexes through a MAP-kinase-dependent pathway: involvement of c-Fos in PACAP-induced Bcl-2 expression. J Neurochem 2006 99: $1237-1250$

31. Yi C, Li S, Chen X, Wiemer EA, Wang J, Wei N et al. Major vault protein, in concert with constitutively photomorphogenic 1 , negatively regulates c-Jun-mediated activator protein transcription in mammalian cells. Cancer Res 2005; 65: 5835-5840.

32. Steiner E, Holzmann K, Pirker C, Elbling L, Micksche M, Berger W. SP-transcription factors are involved in basal MVP promoter activity and its stimulation by HDAC inhibitors. Biochem Biophys Res Commun 2004; 317: 235-243.

33. Lange $\mathrm{C}$, Walther W, Schwabe H, Stein U. Cloning and initial analysis of the human multidrug resistance-related MVP/LRP gene promoter. Biochem Biophys Res Commun 2000; 278: 125-133.

34. Steiner E, Holzmann K, Pirker C, Elbling L, Micksche M, Sutterluty H et al. The major vault protein is responsive to and interferes with interferon-gamma-mediated STAT1 signals. J Cell Sci 2006; 119: 459-469.

35. Mossink MH, van Zon A, Franzel-Luiten E, Schoester M, Kickhoefer VA, Scheffer GL et al. Disruption of the murine major vault protein (MVP/LRP) gene does not induce hypersensitivity to cytostatics. Cancer Res 2002; 62: 7298-7304.

36. Cross TG, Scheel-Toellner D, Henriquez NV, Deacon E, Salmon M, Lord JM. Serine/ threonine protein kinases and apoptosis. Exp Cell Res 2000; 256: 34-41.

37. Chen YR, Tan $\mathrm{TH}$. The c-Jun N-terminal kinase pathway and apoptotic signaling (review) Int J Oncol 2000; 16: 651-662.

38. Behrens A, Sibilia M, Wagner EF. Amino-terminal phosphorylation of C-Jun regulates stress-induced apoptosis and cellular proliferation. Nat Genet 1999; 21: 326-329.

39. Derijard B, Hibi M, Wu IH, Barrett T, Su B, Deng T et al. JNK1: a protein kinase stimulated by UV light and Ha-Ras that binds and phosphorylates the c-Jun activation domain. Cell 1994; 76: 1025-1037.

40. Kyriakis JM, Banerjee P, Nikolakaki E, Dai T, Rubie EA, Ahmad MF et al. The stressactivated protein kinase subfamily of C-Jun kinases. Nature 1994; 369: 156-160.

\section{Supplementary Information accompanies the paper on Cell Death and Differentiation website (http://www.nature.com/cdd)}

